\title{
Accelerating the Rate of Progress in Reducing Mental Health Burdens: Recommendations for Training the Next Generation of Clinical Psychologists
}

Howard Berenbaum, University of Illinois at Urbana-Champaign

Jason J. Washburn, Northwestern University Feinberg School of Medicine

David Sbarra, University of Arizona

Kathleen W. Reardon, The Family Institute at Northwestern University

Tammy Schuler, Fred Hutchinson Cancer Research Center

Bethany A. Teachman, University of Virginia

Steven D. Hollon, Vanderbilt University

Marc S. Atkins, University of Illinois at Chicago

Jessica L. Hamilton, University of Pittsburgh

William P. Hetrick, Indiana University - Bloomington

Jennifer L. Tackett, Northwestern University

Meghan W. Cody, W. G. (Bill) Hefner VA Medical Center

Robert K. Klepac, Wilford Hall Ambulatory Surgical Center

Steve S. Lee, University of California, Los Angeles

\section{Author Note}

Howard Berenbaum led the preparation of this paper and is listed as first author. Jason J. Washburn and David Sbarra made particularly notable contributions to this paper and are listed second and third, respectively. The order of the remaining authors was determined at random. Howard Berenbaum, Department of Psychology, University of Illinois at Urbana-Champaign; Jason J. Washburn, Department of Psychiatry and Behavioral Sciences, Northwestern University 
Training Clinical Psychologists

Feinberg School of Medicine; David Sbarra, Department of Psychology, University of Arizona;

Kathleen W. Reardon, Center for Applied Psychological and Family Studies, The Family Institute at Northwestern University; Tammy Schuler, Fred Hutchinson Cancer Research Center; Bethany A. Teachman, Department of Psychology, University of Virginia; Steven D. Hollon, Department of Psychology, Vanderbilt University; Marc S. Atkins, Institute for Juvenile Research, University of Illinois at Chicago; Jessica L. Hamilton, Department of Psychiatry, University of Pittsburgh; William P. Hetrick, Department of Psychological and Brain Sciences, Indiana University - Bloomington; Jennifer L. Tackett, Department of Psychology, Northwestern University; Meghan W. Cody, Mental Health and Behavioral Sciences, W. G. (Bill) Hefner VA Medical Center; Robert K. Klepac, Wilford Hall Ambulatory Surgical Center; Steve S. Lee, Department of Psychology, University of California, Los Angeles

We appreciate the thought provoking and helpful comments provided by numerous individuals, who shall remain anonymous, over the course of preparing this paper. This paper originated as a collaboration among colleagues affiliated with the Coalition for the Advancement and Application of Psychological Science (CAAPS).

This paper is dedicated to the memory of the late Varda Shoham.

Correspondence concerning this article should be addressed to Howard Berenbaum, University of Illinois at Urbana-Champaign, 603 E. Daniel St., Champaign IL 61820. E-mail: hberenba@illinois.edu 


\begin{abstract}
Despite criticisms dating back to the 1950 s, and minimal progress reducing mental health burdens, the dominant training model in clinical psychology has not changed. We argue that for clinical psychologists to reduce mental health burdens, they (collectively) need to devote a much larger proportion of their professional efforts to a broader range of activities, particularly prevention. We propose a highly flexible two-phase model for clinical psychology training. The initial Foundational Knowledge and Competency Phase focuses on foundational concepts in the science of clinical psychology and direct client care. During the Focused Competency Phase, students may continue training for traditional roles in providing direct client care or, alternatively, develop other roles for using psychological science to address mental health conditions.
\end{abstract}

Key words: clinical psychology; training; mental health burdens

\title{
Public Health Significance
}

Clinical psychology has made little progress reducing mental health burdens. To address this shortcoming, we recommend that clinical psychologists (collectively) devote a much larger proportion of their professional efforts to a broader range of activities than they have in the past. A flexible two-phase model for clinical psychology training is proposed to realize this goal. 
Training Clinical Psychologists

\section{Accelerating the Rate of Progress in Reducing Mental Health Burdens: \\ Recommendations for Training the Next Generation of Clinical Psychologists}

Clinical psychology ${ }^{1}$ is both a discipline and a profession. As an academic discipline, it encompasses the scientific study of: (a) psychopathology and related problems in living; and (b) the complementary goals of promoting well-being and reducing, and ultimately eliminating mental health burdens. As a profession, it is defined by the American Psychological Association (APA) as "the psychological specialty that provides continuing and comprehensive mental and behavioral health care for individuals and families; consultation to agencies and communities; training, education and supervision; and research-based practice" (APA, 2019).

Even though the vast majority (89\%) of health service psychologists provide direct client care, which along with administrative/management activities account for a large majority (72\%) of their time during a workweek (Hamp et al., 2016), clinical psychologists engage in a wide variety of professional activities, such as directing clinics, programs, and agencies; supervising (both other professionals and paraprofessionals); consulting; developing and evaluating public policy; developing and evaluating new programs; implementing and disseminating programs/interventions; generating new knowledge by conducting research; and disseminating knowledge to students/trainees, other professionals, and the general public. We argue that anyone who has obtained foundational knowledge and competency (Rodolfo et al., 2005 ${ }^{2}$ in clinical psychology (which we describe below), along with advanced training in the application of psychological principles, should be considered a clinical psychologist, assuming their

\footnotetext{
${ }^{1}$ Although this paper focuses exclusively on clinical psychology, the issues raised and recommendations proposed may be applicable to counseling and school psychology, with the three disciplines commonly referred to as Health Service Psychology.

${ }^{2}$ We use the term "foundational competency" in a generic sense - we are not referring to the six specific foundational competency domains described by Rodolfo et al. (2005).
} 
professional activities focus on the application of that knowledge to promote well-being and reduce mental health burdens. ${ }^{3}$

The premise of our paper can be summarized as follows. First, in the wake of World War II, clinical psychology in the United States experienced a rapid increase in size and shifted its focus from intellectual and personality assessment to the broader provision of direct client care (i.e., implementing psychological assessments and interventions with clients). Second, although it has helped numerous individuals, the burden of mental health conditions has not declined and, in fact, continues to rise more or less unabated. In addition to the persistently high prevalence rates of mental health disorders and the large gap in services received by those in need (see the section of the paper titled “The Burden of Mental Health Conditions"), Kazdin \& Blasé (2011) note the high cost in unmet need and lack of productivity with estimates of $\$ 500$ billion for the cost of services and almost $\$ 200$ billion in productivity loss. In addition, suicide rates in the U.S. have increased in the past decade for both adults (Woolf \& Schoomaker, 2019) and youth (Curtin \& Heron, 2019), with recent rates for military veterans outpacing civilians for the first time on record (Smith et al., 2019). The NIMH estimates that nearly 50 million U.S. adults suffer from a mental health disorder. Clearly, mental health conditions are serious and highly prevalent public health concerns, and these issues represent an enormous unmet burden both in the U.S. and globally (https://www.nimh.nih.gov/health/statistics/mental-illness.shtml.). Third, there is little reason to expect the status quo to significantly reduce the burden of mental health conditions rather, meaningful change is needed if clinical psychology is to contribute to significantly

\footnotetext{
${ }^{3}$ The activities aimed at promoting well-being and reducing mental health burdens may have an immediate impact (e.g., disseminating interventions, supervising paraprofessionals) or may be expected to have an impact in the long run (e.g., conducting mental health policy analysis, carrying out research).
} 
reducing mental health burdens. Finally, the changes that are most likely to enable clinical psychology to make significant progress reducing mental health burdens will require a marked increase in the proportion of clinical psychologists who engage in professional activities other than direct client care and traditional research. What we believe is particularly needed, not just by clinical psychologists but by the health care system more broadly, is a shift from a primarily disease management approach to one of health promotion.

What we mean by "traditional" research is the scientific work typically conducted in Departments of Psychology and Psychiatry aimed at generating generalizable knowledge. It is likely that clinical psychologists' professional activities that go beyond traditional research and direct client care, such as public health policy analysis, administration, and prevention efforts, will include research, though often not exclusively for the purpose of generating generalizable knowledge. For example, someone working in a public health department could conduct research to generate and refine an algorithm for determining allocation of different levels of care; someone in a leadership position in a healthcare system may collect and analyze data as part of a quality improvement project for a new system-wide initiative; someone working for a local school district or municipal park system could conduct research to determine the level of interest in alternative prevention programs.

Currently, it is common for clinical training programs to be viewed through the lens of research vs. practice. Consequently, we anticipate that many readers will be inclined to view our proposal through a similar lens. However, our proposal is not intended to privilege or to expand traditional research or practice. To the extent that our proposal is enacted and leads to greater flexibility and creativity, we expect it to benefit training in research and practice, as well as areas beyond traditional research and practice. In other words, to effectively reduce the burden of 
mental health conditions, the field needs to move beyond the notion of graduate programs falling somewhere on a research vs. practice continuum. To accomplish this goal, we propose that clinical psychologists expand the ways in which they can contribute to the reduction of mental health burdens.

We present a proposal intended to increase flexibility and creativity in the training of the next generation of clinical psychologists; the changes that follow from this proposal will enable clinical psychologists to more easily and successfully engage in a wide range of professional activities. Our proposal is intended to be equally applicable to Ph.D. and Psy.D. training programs. The most important aspects of our proposal are that: (a) doctoral training be divided into two phases, each of which would take approximately 2-3 years to complete; (b) a Foundational Knowledge and Competency Phase would provide basic coverage of domains such as psychopathology, assessment, intervention, and ethics (discussed below), and would provide all clinical psychology graduate students with competencies in the assessment and treatment of most highly prevalent forms of psychopathology; (c) during the Focused Competency Phase, students would obtain more specific and individualized training consistent with the professional roles they wish to pursue as doctoral level clinical psychologists; (d) students need not obtain any further training in direct client care during the Focused Competency Phase; (e) clinical psychology training programs need not prepare all - or even any - students for careers that predominantly focus on direct doctoral level client care; (f) all training not provided by doctoral programs can be postdoctoral (i.e., there will be no predoctoral internship $\left.{ }^{4}\right)$; $(\mathrm{g})$ many students

\footnotetext{
${ }^{4} \mathrm{We}$ are not the first to propose that the internship be postdoctoral. In fact, slightly more than 20 years ago, the Council of University Directors of Clinical Psychology (CUDCP) voted to make the internship postdoctoral, but the Association of Psychology Postdoctoral and Internship Centers (APPIC) voted to keep the internship predoctoral (Boggs \& Douce, 2000).
} 
(necessarily including, but not necessarily limited to, those whose careers will focus on direct doctoral-level client care) will pursue full-time postdoctoral training experiences such as those currently offered by members of the Association of Psychology Postdoctoral and Internship Centers (APPIC), whereas others will pursue postdoctoral training experiences that focus on different approaches for having a public health impact (e.g., influencing policy); and (h) if enacted, our proposal will lead to few, if any, changes in the training of clinical psychologists whose careers will focus on direct client care, but large changes for those who want to apply their training beyond direct client care. Over time, we expect that more students will select career paths other than direct client care and research if doctoral programs offer greater flexibility in preparing them for those alternate career paths. We also expect that new alternate career paths will be identified as doctoral programs become increasingly innovative and interdisciplinary. Although we focus our recommendations on changes to clinical psychology doctoral programs, both to keep the scope manageable and because of our collective expertise in this field, we recognize that many of our recommendations may also apply to other allied fields (e.g., industrial/organizational psychology, social work) given the need to coordinate efforts to efficiently address the complexities of reducing mental health burdens.

After presenting our proposal, we discuss the future of education and training in clinical psychology. Our goal for this paper is to start an open discussion about the future of clinical psychology, one that will involve all relevant stakeholders and constituencies from the outset. Our hope is that these conversations can begin taking place on an open discussion forum online and extend to other venues, including special issues of journals, dedicated conferences, and white papers outlining the procedural changes and a timetable for the reorganization of graduate programs, accreditation, and professional licensure. 
Training Clinical Psychologists

\section{The Premise}

\section{$\underline{\text { Brief Historical Overview }}$}

Although contemporary clinical psychology is strongly associated with assessment and psychotherapy practice (Benjamin, 2005), this was hardly the sole thrust of clinical psychology at its origins. For example, the founder of American clinical psychology, Lightner Witmer, "conceived the role of clinical psychologists as extending well beyond the consulting room. In addition to intervening in schools, Witmer argued that clinical psychologists should engage in preventive social action to change harmful social conditions" (Humphreys, 1996, p. 190). Clinical psychologists continued to play numerous roles across a wide range of settings through the 1930s (Humphreys, 1996). However, the need for direct client care became increasingly salient during and immediately following World War II, leading to a shift of clinical psychologists into the realm of psychotherapy (Benjamin, 2005). In the 1940s and 1950s, the roles of clinical psychologists outside of academia shifted almost entirely to the direct provision of services for individual clients or entities (i.e., dyads, families, groups). By the 1960s and 1970s, clinical psychologists had become well established in private practices and had near parity with psychiatry - as described by Benjamin (2005), "the golden age of clinical psychology had arrived" (p. 22). The golden age, however, quickly ended as managed care began to have an impact on clinical psychology in the 1980s (Benjamin, 2005), and competition from master's level clinicians, both within and outside of psychology, has increased ever since (Cummings, 1995).

The current template for the training of clinical psychologists emerged in the late 1940s and was shaped by the emerging emphasis on the direct provision of services, especially psychotherapy. The federal government charged the Department of Veterans Affairs (VA) and 
the United States Public Health Service (USPHS) to work with the American Psychological Association to develop and review doctoral training programs in clinical psychology. In the summer of 1949, a conference at the University of Colorado, Boulder, convened experts to perform four key activities: (1) outline a program for training in clinical psychology; (2) formulate instructional standards in clinical psychology for both universities and practicum sites; (3) evaluate and oversee training programs, including writing a report of each institution; and (4) liaise with other organizations on mental health problems (Committee on Training in Clinical Psychology, 1947). Three key points in what evolved to become the "Boulder model" (Committee on Training in Clinical Psychology, 1947) are particularly relevant to the future of training in clinical psychology: (1) an explicit emphasis on providing trainees with foundational expertise that could be leveraged into specialization later in their training; (2) cautioning against a one-size-fits-all training model and instead affording training programs considerable flexibility in attending to specific goals and needs; and (3) the importance of science informing practice, and practice informing science. In recognition of this interplay between science and practice, the Boulder model is commonly referred to as the scientist-practitioner model.

Several alternative models intended to re-think training in clinical psychology have been developed and implemented since the Boulder model, including the scholar-practitioner and clinical science models (e.g., Levenson, 2017; Baker et al., 2008; Peterson et al., 1997). However, all training models as currently implemented have their roots in the Boulder model and share much of their training in common. For example, currently all doctoral and internship programs in clinical psychology in the United States are designed to prepare students for entry level clinical practice. In psychology, "clinical practice" has come to refer to the direct delivery of services, most often in the form of psychotherapy and psychological evaluation. In fact, the 
"practice of clinical psychology" has a specific legal meaning in many states. For example, in Illinois, the "practice of clinical psychology" is "subject to regulations in the public interest to protect the public from persons who are unauthorized or unqualified to represent themselves as clinical psychologists or as being able to render clinical psychological services as herein defined, and from unprofessional conduct by persons licensed to practice clinical psychology" (225 ILCS 15/1). Thus, clinical practice, as it has come to be defined, represents only a subset of the range of applications of the academic discipline of clinical psychology.

\section{The Burden of Mental Health Conditions}

As pointed out by others, including in a highly influential paper by Kazdin and Blase (2011), rates of mental disorders remain high and largely stable, and the global burdens associated with mental health conditions appear virtually unaffected by empirical advances in prevention and treatment. Across the globe, nearly $20 \%$ of people meet diagnostic criteria for a common mental disorder (typically defined as a mood, anxiety, or substance use disorder) in any given year, and close to $30 \%$ of people have experienced a common mental disorder in their lifetime (Steel et al., 2014). Cross-national epidemiological data illustrates almost no change in the point prevalence of diagnosable anxiety disorders or major depressive disorder between 1980 and 2009 (Baxter et al., 2014), and after a period of decline, deaths from suicide have increased $30 \%$ from 2000 to 2016, especially among adolescent girls (Hedegaard et al., 2018). Thus, the burden of mental health conditions is enormous, and if anything, continues to increase, impacting national economies, personal finances, lost work days, family dynamics, prison systems, personal 
employability, and many other factors that affect quality of life and functioning across the United States and worldwide ${ }^{5}$ (Trautmann et al., 2016; Vigo et al., 2016).

Two factors, also noted by others, contribute in significant ways to the failure to reduce the burden of mental health conditions: (a) the mental health treatment gap; and (b) insufficient attention to prevention (e.g., Albee, 1990; Atkins \& Frazier, 2011; Kazdin \& Blase, 2011). The mental health treatment gap is the discrepancy between those who have mental health conditions and those who receive treatment for mental health conditions. For example, in the United States, only between $15 \%$ and $30 \%$ of people in need of mental health services actually receive any (Kessler et al., 2005), with racial and ethnic minorities especially unlikely to receive services (e.g., Satcher, 2001). Notably, the treatment gap is substantially higher in poorer countries. For example, in China only approximately $3 \%$ of people in need of mental health services actually receive any, and in Nigeria less than 1\% receive services (World Health Organization [WHO] World Mental Health Survey Consortium, 2004).

The mental health treatment gap is largely the result of substantial barriers to treatment and shortages of mental health professionals. There are numerous barriers to treatment, including financial (e.g., Kessler et al., 2001), geographic (e.g., Andrilla et al., 2018; Cummings et al., 2017), and cultural (e.g., Leong \& Kalibatseva, 2011). Perhaps the most important barrier was noted by Kazdin (2019), who wrote, "a key barrier is the dominant model of delivering psychosocial interventions. That model includes one-to-one, in-person treatment, with a trained mental health professional, provided in [a] clinical setting (e.g., clinic, private practice office,

\footnotetext{
${ }^{5}$ Even if one conceptualizes mental health from a dimensional perspective, and assumes that there will always be a continuum of mental health with some individuals falling at both ends of the continuum, we believe it should be the mission of clinical psychology to reduce absolute levels of distress and disability, including objective outcomes such as suicide rates (which, as already noted, are increasing).
} 
health-care facility). That model greatly limits the scale and reach of psychosocial interventions" (p. 455). Kazdin and colleagues (Kazdin, 2017, 2019; Kazdin \& Blase, 2011; Kazdin \& Rabbitt, 2013) describe a wide variety of alternatives to the dominant model of psychosocial intervention delivery, including changes to who delivers interventions, where interventions are delivered, and the nature of the interventions. Even if there were no barriers to treatment, the discrepancy between need and availability would be immense. As noted by Albee (1990), the reason psychotherapy cannot solve mental health problems in the United States is not that psychotherapy does not work, but rather because of the "unbridgeable gap between the enormous number of people with serious emotional problems and the small number of therapists available" (p. 370 ). In the United States, approximately $25 \%$ of the population (approximately 80 million people) suffer from a mental disorder in any 12 -month period, while there are only slightly over 100,000 licensed doctoral level psychologists (Lin et al., 2016). The discrepancies in poorer countries, including many of the most populous countries in the world (such as China, India, Indonesia, Pakistan, Nigeria, and Bangladesh, which collectively account for approximately twothirds of the world's population), are orders of magnitude greater. This person-power shortage has been known for at least 60 years (Albee, 1959), yet demand for psychologists, and mental health services more broadly, will likely continue to exceed supply over the next two decades (Bureau of Labor Statistics, U.S. Department of Labor, 2018; U.S. Department of Health and Human Services, 2016). Behavioral health workforce shortages are expected to continue until at least 2025, at which point it is estimated that the shortage of clinical, counseling, and school psychologists is expected to reach almost 60,000 and the shortage of all behavioral health professionals is expected to be approximately one quarter of a million (National Academies of Sciences, Engineering, and Medicine, 2017). The impact of COVID-19 on mental health 
problems has exacerbated the mental health treatment gap and has further revealed the need for clinical psychologists to be capable of responding in novel, creative ways (Gruber et al., 2020).

There can be little doubt that the most efficient means of reducing the burden of mental health conditions would be to reduce their incidence. According to the National Prevention Council (2011), "preventing disease and injuries is key to improving America's health" (p. 6), and according to the American Psychological Association's Guidelines for Prevention in Psychology (2014), "the effectiveness of prevention to enhance human functioning and reduce psychological distress has been demonstrated" (p. 285). Psychology and other mental health professions have taken two approaches to prevention: public health (population-level interventions) and developmental (modifying risk and resilience across individuals' growth trajectories; Beck \& Cody, 2016). Both approaches use a three-stage prevention research cycle, consisting of: (a) etiological studies of risk and resilience factors; (b) clinical trials of preventive interventions; and (c) implementation and dissemination of preventive interventions into the community. To date, the vast majority of work on the prevention of mental disorders falls within the first two stages of the cycle, with the dissemination of newly developed effective interventions identified as a priority for psychologists over the next decade (Muñoz, Beardslee, \& Leykin, 2012).

Recommendations for accelerating progress in prevention science emphasize new activities and roles for psychologists, including development and implementation of interventions led by paraprofessionals, integrating mental health promotion and universal prevention into primary health care settings, and expanding the focus of prevention programs from individual-level targets to larger social/environmental systems (Beck \& Cody, 2016). Even though prevention efforts will be critical to reducing the burden of mental health conditions, since the Boulder 
Conference, the education, training, and practice of clinical psychologists have emphasized direct client care for people who have already developed mental health conditions.

The evidence appears clear: to significantly reduce the burden of mental health conditions, it will be necessary to both move beyond the current dominant model of delivering psychosocial interventions one-to-one in traditional clinical settings and to increase attention to prevention. Indeed, Atkins and Frazier (2011), argued that it is critical for clinical psychology to develop a “comprehensive and integrated public health model." As an illustration with children's mental health services, these authors proposed that resources be distributed equitably across the continuum from prevention to intervention, including mental health promotion at the universal level, prevention focused on natural settings (e.g., school districts and parks), targeted interventions that prioritize care for high-risk groups, and evidence-based treatments that can be delivered with high fidelity in community settings. If such an approach were to be employed more broadly, clinical psychologists could contribute to reducing mental health burdens in a wide variety of ways, including: (a) continuing to directly deliver evidence-based treatments to people who have already developed mental health conditions; (b) leading and training others to deliver evidence-based prevention programs and treatments; (c) developing, implementing, and disseminating more effective and efficient evidence-based interventions; (d) conducting research intended to lead to the development of improved interventions, especially those that extend beyond one-to-one, in-person interventions in traditional settings, such as direct-to-user digital interventions; (e) developing and implementing improved means of identifying those at highest risk for mental health conditions; (f) working to develop and implement prevention efforts in non-clinical/medical settings, ranging from barber shops and hair salons (see Victor et al., 2018) to social media platforms and embedded sensors in personal computing devices; and (g) using 
clinical psychological science to inform public policy (see Novak \& Brownell, 2011, for an example).

\section{Clinical Psychology is at a Crossroads}

As we see it, clinical psychology is faced with a choice. One option is to continue with the status quo. Clinical psychology would continue to be a noble profession, with clinical psychologists providing relief to a subset of people who have already developed mental health conditions. But the status quo has not - and cannot - be expected to significantly reduce mental health burdens. Moreover, given the substantial resources necessary to educate and train clinical psychologists, providing direct client care by clinical psychologists will be hopelessly inadequate for addressing the burden of mental health conditions in under-resourced countries (that include the large majority of the world's population) where the current per capita number of mental health professionals is a tiny fraction of that in wealthy countries.

Another option is for the field to move in ambitiously innovative directions that have the potential to significantly reduce mental health burdens worldwide. Clinical psychology is well positioned to do so - clinical psychologists have a long history of playing a wide variety of roles other than direct client care, such as engaging in prevention efforts, training multiple professions and non-professionals to deliver evidence-based interventions, and engaging in mental health policy analysis. The goal of our proposal is to facilitate these different ways of making an impact, as well as to encourage the development of new and innovative ways to reduce the burden of mental health conditions. Furthermore, clinical psychology has long focused on understanding the multiple contributions to mental health outcomes, from the molecular level to the environment and social context (e.g., Baer et al., 1968; Gottesman \& Shields, 1972). There is growing evidence that life experience and the environment influence gene expression (i.e., 
epigenetics; e.g., Lau \& Eley, 2010; Morrison et al., 2019) and brain development and functioning (e.g., Koss \& Gunnar, 2018; Struber et al., 2014). By building more flexibility into doctoral training so that new areas of inquiry can more readily be examined, clinical psychology can play a critical role in conducting and then harnessing the scientific study of these large forces - e.g., the intersection of neuroscience and genetics with environmental and social factors - to promote a new understanding of prevention and treatment possibilities (e.g., Fisher et al., 2016).

Clinical psychology is also at a crossroads in terms of the utilization of digital and mobile technology for assessment, prevention, and treatment of mental health conditions (Fairburn \& Patel, 2017; Marzano et al., 2015; Mohr et al., 2017), just as are other areas of health. As the World Health Organization (2011) noted, "The use of mobile and wireless technologies to support the achievement of health objectives (mHealth) has the potential to transform the face of health service delivery across the globe" (p. 1). Importantly, novel digital mobile health and web-based approaches, ranging from real-time autonomous interventions using wearable sensors or self-tracking technologies to clinician-supported digital interventions, have the potential to radically change what intervention looks like and address the severe limitations of the one-onone, in-person assessment and intervention model that currently dominates clinical psychology (Kazdin \& Blase, 2011). The WHO (2011) estimates that there are over 5 billion wireless subscribers globally, with $70 \%$ of them residing in low- and middle-income countries, and commercial wireless signals cover over $85 \%$ of the world's population. Accordingly, clinical psychology is faced with an opportunity to greatly expand its impact by incorporating research and practical training that will enable its graduates to alleviate the burden of mental health conditions through innovations in digital and mobile health. 
Mobile health and other alternative delivery models will only be one part of the solution. Innovation, with or without technology, is desperately needed to address the burden of mental health conditions. A critical argument for innovation, and perhaps even a roadmap, is inspired by the early history of clinical psychology. As noted earlier, one of the founders of American clinical psychology, Lightner Witmer, envisioned clinical psychologists working in a variety of settings, and not only treating individuals, but also targeting environmental factors that contribute to psychological problems. Sarason (2003), writing as one of the last surviving participants in the Boulder Conference, lamented the disregard for the promotion of wellness and the prevention of problems. He noted the need for clinical psychology to return to its roots and to encourage engagement in a broader range of activities. However, for clinical psychologists to take this leap, significant changes will need to be made to training programs in clinical psychology.

\section{The Proposal}

In keeping with the views of the framers of the Boulder model that a one-size fits all approach be avoided, we recommend that the training of the next generation of clinical psychologists be as flexible as possible. Also consistent with the framers of the Boulder model, we propose that all trainees be provided with foundational knowledge and competencies, followed by focused training and specialization guided by students' interests and career goals as well as emerging public health needs. The foundational competencies should provide skills that can be applied broadly and flexibly throughout their career, including in ways we currently may not be able to imagine. Our proposal is also consistent with one of the hallmarks of the Boulder model, that science and the application of psychological science inform one another. 
Most notably, we argue that not every clinical psychology training program needs to prepare all - or even any - students for careers that predominantly focus on direct client care. Instead, we propose that the field embrace a plurality of training models, including new and innovative models. To accomplish this, programs will need the latitude to prepare students for myriad careers and to engage in a wide range of activities. Some clinical psychology training programs will continue to expect most or all of their graduates to pursue traditional careers devoted primarily to direct client care. Alternatively, other programs may choose to focus their education and training on activities that do not involve direct client care, such as the development and utilization of large-scale digital and mobile health services, primary prevention, public policy, or implementation/dissemination. Although we propose that all students obtain foundational knowledge and competencies in the delivery of behavioral health services, doctoral programs should not be required to prepare students for careers that emphasize direct client care.

We propose that the ten domains described in Appendix 1 constitute core foundational learning domains across doctoral programs in clinical psychology. Not surprisingly, the ten domains described in Appendix 1 overlap considerably with what is currently covered in virtually all clinical psychology doctoral programs. In Appendix 1, we provide the rationale for covering these domains, ways in which coverage of these domains has evolved and is likely to evolve in the future, and ways in which programs may currently cover these domains differently.

What we think is most important is not the list of domains, but rather our call for greater flexibility in how these domains are covered. To maximize flexibility, we recommend that: (a) training programs be given latitude in how they go about providing training in these domains (including the quantity and format of training in each domain) - competencies in these areas can be achieved in a variety of ways, and it is up to doctoral programs to ensure students' 
competencies and to achieve these competency endpoints as they see fit; (b) programs be permitted, if not encouraged, to customize training in each domain to the career goals of the individual student, particularly for those students not pursuing a career involving direct client care; and (c) training programs not be required to provide training beyond these domains. $\underline{\text { A New Multi-Phase Training Model for Clinical Psychologists }}$

We propose that doctoral training in clinical psychology be divided into two phases, each of which would take approximately $2-3$ years to complete. ${ }^{6}$ The first phase, which we refer to as the Foundational Knowledge and Competency Phase, would cover the essentials of the 10 domains described in Appendix 1. This first phase would also provide all clinical psychology graduate students with a foundational level of competency in delivering science-based methods for diagnosing mental disorders, identifying transdiagnostic markers of vulnerability and dysfunction, case conceptualization, treatment planning, transdiagnostic prevention and intervention strategies, and outcome monitoring for highly prevalent problem areas. Thus, this first phase will enable programs to continue providing an integrated training period during which the curriculum covers both the foundational competency/knowledge components and hands-on training in direct service delivery.

Developing these direct service delivery competencies during the foundational phase is feasible, as there is mounting evidence that competence in delivering common elements of therapeutic change can be achieved in substantially less time than is typical in a doctoral program in clinical psychology. For example, a recent systematic review found a pooled effect size of $0.49(\mathrm{CI}=0.36-0.62)$ for psychological treatments of common mental disorders that were

\footnotetext{
${ }^{6}$ Ultimately, the length of time required for each phase of graduate training should be determined on the basis of the length of time needed to obtain competence.
} 
delivered by health workers without specialized mental health training (Singla et al., 2017). These non-specialist providers achieved medium to large effects after receiving about 80 hours of training in delivering established elements of therapeutic change. Thus, it seems very realistic that within the 2-3 years of the Foundational Knowledge and Competency Phase, students could develop foundational competencies in the assessment and treatment of most highly prevalent forms of psychopathology (e.g., mood, anxiety, and substance use disorders). Assuming such competencies are sufficient to obtain Master's level licensure to deliver services, we expect that completion of the Foundational Knowledge and Competency Phase would provide all students with the option of obtaining such licensure, even prior to completion of their doctoral studies.

The essential knowledge and training in clinical psychology provided during this foundational phase would provide the base upon which a student would then engage in focused training in an area of specialization during their second phase of graduate training, as well as for further specialization ${ }^{7}$ and shifts in interests over the course of a career. ${ }^{8}$ We refer to the second phase of education and training in clinical psychology as the Focused Competency Phase, during which students obtain more specific and individualized training consistent with the professional roles they wish to pursue as doctoral level clinical psychologists. During this second phase, students will continue to receive training in at least some of the 10 domains described above. However, during this phase, the domains that are covered will vary from student to student, and such training is expected to be more advanced and customized to students' specific career interests.

\footnotetext{
${ }^{7}$ Some graduates of clinical psychology doctoral programs may choose to return to school to respecialize at a later point in their career, and some training programs may develop specialized programs for this purpose.

${ }^{8}$ A comparison with training models in Europe is presented in Appendix 2.
} 
For some students, the focused training during this second phase will be in some area(s) of direct client care (akin to the current norms), whereas for other students this focused training need not include any direct client care. This approach will allow programs to develop, in a nimble and unconstrained manner, innovative training programs in response to the latest research, technology, policy, and healthcare trends. Moreover, this approach will allow for a depth of study that we believe is essential to prepare clinical psychologists to have a meaningful impact on mental health burdens. Our argument is that many more opportunities will exist if the graduate training structure in the field is more flexible and less time is spent preparing all students for internship as a predoctoral requirement. We anticipate that this model will result in a greater variety of programs available to clinical psychology students, as well as the types of careers that students could pursue. For example, programs may prepare students for careers in: mental health economics and policy; dissemination of best psychological knowledge and practices; developing, implementing, and evaluating mobile and digital mental health interventions; and leadership roles in community mental health. This model provides the time and flexibility for programs to prepare students for a wider variety of careers than is currently possible, allowing clinical psychology to be more responsive to developments in the health needs of the population, as well as advances in our knowledge.

In comparison to the current model of training, our proposal will likely result in greater variation in what knowledge is taught and what skills are trained across both programs and students, particularly during the Focused Competency Phase. Programs and students will continue to share a strong focus on the application of scientific knowledge and psychological principles to whatever work they do (e.g., direct client care, mental health policy analysis, implementation and dissemination). Similarly, all students would continue to participate in 
practica during the Focused Competency Phase, though the nature of the practica will vary. Some students, particularly those intending to pursue careers as providers of direct client care, will complete practica involving direct provision of psychological assessment and intervention. As is the case now, students planning careers as providers of direct client care would take practica focusing on direct client care throughout most of graduate school. In contrast, for those students pursuing career paths other than direct client care as a doctoral-level clinical psychologist, extensive training in direct client care beyond that provided during the Foundational Knowledge and Competency Phase likely makes little sense. For example, a student whose career goal is to work in government or as part of a policy think-tank to develop and evaluate health policies aimed at reducing the burden of mental health conditions would be better served by taking courses in social and political psychology, epidemiology, and health policy, and by taking practica in government settings (e.g., as a part-time aide to a state legislator). As this example demonstrates, although all students will take some form of practica during the Focused Competency Phase, the focus of the practica during this phase need not be in the provision of direct client care.

Implications for postdoctoral training, internship, and beyond. It will be incumbent on doctoral training programs in clinical psychology to ensure that their graduates are well prepared for and can succeed in existing and, in many cases, yet-to-be-discovered, career paths that promote science to understand, reduce, and prevent mental health burdens, and to foster adaptive development and well-being. Those students who wish to pursue careers providing direct client care will be expected to complete a relevant full-time training experience such as those currently offered by members of the Association of Psychology Postdoctoral and Internship Centers (APPIC). To maximize flexibility and promote innovation in doctoral training programs, we 
Training Clinical Psychologists

propose that pre-doctoral internships, which currently focus on training students to provide direct client care, become post-doctoral (consistent with most other health professions), rather than remain integrated into the doctorate. Students with goals and career paths that include direct client care would complete a postdoctoral fellowship that would be functionally equivalent to current internships, allowing those students to pursue licensure at the doctoral level, and ultimately board certification in their area of specialty. By moving to a postdoctoral model, with foundational competencies in direct client care having already been established during the Foundational Knowledge and Competency Phase, these direct client service training experiences during the postdoctoral fellowship could provide more focused training in specialties and subspecialties in clinical psychology.

Students who do not plan to pursue careers in direct client care could pursue a variety of postdoctoral training experiences, the precise nature of which would depend on their goals and career paths. For example, someone whose career goal is to work with Non-Governmental Organizations (NGOs) in low- and middle-income nations would benefit more from full-time training in the field with NGOs (e.g., internship at the WHO) than by pursuing a traditional internship. Likewise, someone whose career goal is to develop and evaluate mental health policies would benefit more from a full-time field experience in a setting that develops or implements mental health policies than from an internship focused on direct service delivery - an example of such an existing postdoctoral fellowship is the SRCD U.S. Policy Fellowship Programs (https://www.srcd.org/professional-advancement/srcd-us-policy-fellowship-programs). Making internships and other full-time, year-long training experiences postdoctoral would provide students the maximum flexibility in curating a training program that is aligned with their goals and interests. Providing doctoral programs with complete control over the training of their 
students prior to graduation would facilitate innovations in graduate training, ultimately making it more likely that clinical psychology could contribute to substantial reductions in the burden of mental health conditions. If the current predoctoral internship (the vast majority of which focus primarily, if not exclusively, on direct service delivery) were to be retained, doctoral programs and their students would need to focus on direct service delivery so that students would be adequately prepared for such internships (and capable of competing for the limited number of slots), and programs and students would be unable to devote the necessary time and attention to career paths other than direct service delivery. Put simply, requiring that all students prepare for and then complete a predoctoral internship that focuses primarily, if not exclusively, on direct service delivery is inconsistent with the goals of our proposal.

It is important to note that the proposed changes to the current structure of the predoctoral internship will lead to few, if any, changes in the training of clinical psychologists who wish to focus on direct client care in their careers. Even those who do not plan to include direct client care in their careers may choose to pursue postdoctoral training that includes direct client care to further their career goals (e.g., clinical leadership, treatment development, dissemination/implementation). However, the proposed changes will make it more feasible for programs and students to train for a wider array of career paths beyond direct client care, should they wish to. In Table 1, we illustrate the required training and credentials, based on our recommendations, for several sample careers/positions.

\section{Identifying and Questioning Assumptions}

Our proposal is intended to encourage flexibility for both training programs and students. This will require questioning our assumptions about training, some of which we may not even recognize. For example, based on how most training programs have operated for decades, some 
might assume that since we list 10 core foundational learning domains that we are prescribing 10 required courses (one per domain). However, there is no reason why training in all, or even any, of the 10 domains need to be provided in the form of traditional classes. In fact, the most compelling evidence suggests that students learn by doing (Davidson, 2017), and this learning can take place in a context that is both problem-oriented and student-centered. Thus, we anticipate less and less training to occur via traditional classroom instruction.

It is likely that many in the field, including the authors, have assumptions about training that extend well beyond the issue of traditional classroom instruction. For example, some may assume that it must be the responsibility of all doctoral level clinical psychology training programs to ensure that its graduates are license-eligible. We are optimistic that should the flexibility and creativity of training in clinical psychology be encouraged, innovation will follow. For example, we would expect that with time, training programs would add new minors and specialization opportunities that focus on ways to apply our skills beyond traditional research and direct client care. We anticipate the emergence of innovative interdisciplinary hybrid programs (e.g., clinical psychology/public policy), jointly housed or sponsored by multiple academic units, that both in principle and in practice are far more than the sum of two separate programs/degrees that already exist. Just as there is potential for synergy when clinical psychology programs combine with other academic units and programs within their home universities, there is enormous potential for cross-institution collaborations. As distance learning and collaboration increases, and if exchange of faculty and students across institutions becomes more common, we can envision "doctorates without borders," with multiple institutions working collaboratively to train the next generation of clinical psychological leaders and innovators.

\section{The Future}


We believe that clinical psychology is at a crossroads. The field can choose to stick to the status quo, focusing primarily on direct one-to-one client care and traditional research. Although this option would enable clinical psychologists to continue helping the few, it would likely preclude clinical psychology from playing an important role in significantly reducing the burden of mental health conditions. Instead, we hope the field chooses to be forward-looking and to make changes that will contribute to significant reductions in mental health burdens. By expanding the breadth of roles to be played by clinical psychologists, and increasing the flexibility of training, our proposal also has the potential to attract a more diverse pool of individuals to the field.

We recognize that the current training model does allow students to obtain some training beyond direct client care and traditional research. However, we believe the proportion of training time dedicated to specific professional roles needs to shift dramatically to allow for greater opportunities beyond direct provision of client care and traditional research. Moreover, this flexibility is needed at multiple stages of training - we propose that programs can elect to use the Focused Competency Phase to target impact areas (e.g., policy, dissemination) that do not involve ongoing training in direct provision of client care or traditional research, and we propose to change the internship model so that it occurs at the post-doctoral level and the focus can be on whatever impact area that graduate wants to specialize in (e.g., it could be direct provision of client care but could just as easily be some other area, such as community prevention work or the development and evaluation of mobile technologies for improving mental health). If the goal is to increase the number of clinical psychologists who engage in professional activities other than direct client care and traditional research, and improve how 
they are trained to do so, we need greater flexibility and innovation, and programs intentionally designed to achieve this goal.

We present the following (admittedly simplistic) analogy to illustrate why proposals like ours are worth trying to implement but have yet to be attempted. Imagine a country in which there existed hundreds of "food and nutrition" training programs which, for odd historical reasons, had as their goal producing graduates who became chefs in restaurants. To obtain their degrees, students had to complete a full-time, year-long internship working in a restaurant as a chef-in-training. Further, it was not possible for a training program to be accredited if all of its students did not complete such internships and were not prepared to be chefs in restaurants upon graduation. Not surprisingly, the vast majority of graduates ended up working as chefs in restaurants, though occasionally a graduate would pursue additional training following graduation so that they could pursue alternative career paths, such as being in charge of food preparation/delivery in institutional settings (e.g., schools) or developing nutrition enhancement programs for community organizations. When, after such programs had existed for more than half a century, it was recognized that the prevalence and impact of nutritional problems had not declined, a number of educators proposed that their programs not be required to train all of their students to work as chefs in restaurants, that not all of their students be required to complete internships in restaurants, and that programs be given the latitude to intentionally train some or all of their students to address nutritional problems through means other than being chefs in restaurants (while retaining foundational training for all of their students in nutrition science and basic food preparation). These educators recognized that if it was desirable to have far more of their graduates engage in professional activities other than being chefs in restaurants, and if they wished to optimally prepare their students for such careers, their programs should devote 
significant effort toward preparing students for such careers, rather than relying on their graduates to re-tool following graduation. Individual training programs were unwilling to implement the proposal because it would mean losing their accreditation. Many were reluctant for the field to adopt the proposal for a variety of reasons: (a) because it would require substantial reorganization of the field — from funding models to accreditation to licensure; (b) because of fears that there would be fewer well-trained chefs in restaurants; and (c) because it had yet to be tried anywhere, and there was no guarantee that implementing the proposal would reduce nutritional problems any more than the old system. But all of the available evidence clearly indicated the old system was not making a substantial dent in the country's nutritional problems, whereas the proposed new system had the potential to do so.

Making changes will be challenging not just because of inertia, but due to fears about modifying a field that has many reasons to be proud. Although we cannot prove, in advance, that eliminating the requirement that all students pursue training for doctoral level direct client care will ultimately lead a greater number of clinical psychologists to engage in professional activities other than direct client care, it seems like a very likely outcome. Some may worry that, if enacted, our proposal will lead to fewer clinical psychologists being providers of direct client care, which will in turn expand rather than reduce the mental health treatment gap. However, estimates of future mental health treatment gaps are based on assumptions regarding incidence rates and means of delivering mental health care. We predict that the loss of clinical psychologists engaged in direct client care will be more than compensated for by the reduction in need that would result from increasing the number of clinical psychologists who engage in prevention and the development of novel means of delivering mental health care. Ultimately, our proposal is based on a public health perspective, shared by others such as the WHO (2011) 
and the National Prevention Council (2011), positing that alternatives to direct client care as currently delivered, such as a shift to prevention and the use of mobile and other emerging technologies, stand the best chance of improving health outcomes at a population level.

We are not, of course, expecting clinical psychology to single-handedly reduce mental health burdens. In fact, one of the most important ways clinical psychology can contribute is by collaborating with professionals in other fields that are relevant to mental health and well-being. To the degree that clinical psychologists have expertise beyond direct client care (e.g., in terms of prevention, public health, and the development and delivery of interventions via mobile technology), we expect them to be more inclined and better able to engage in interdisciplinary work with professionals in other fields to influence mental health care practice and policy. Although we do not think clinical psychologists are unique in their ability to engage in interdisciplinary work and to contribute in novel ways to reduce mental health burdens, we do believe they are particularly well positioned to do so given psychology's breadth (from molecules to communities) and its historical attention to prevention.

Although we hope the field can move in new directions, and we believe there is merit to our proposal, we are not so presumptuous as to believe that our proposal is perfect. We are open to the possibility that alternative training models may have an equal or greater likelihood of enabling clinical psychology to contribute to reducing mental health burdens. We view this paper as the beginning of a discussion and process of change, not as an end-point. We are hoping this paper will begin a conversation, to be continued via an open online discussion, about the future of clinical psychology.

We recognize that implementing changes will be quite challenging and the practical demands of restructuring the field will be daunting. By far the biggest changes would need to be 
made by doctoral training programs. For example, how, if at all, would individual programs choose to structure their curricula? For programs that wish to continue preparing all or the vast majority of their students for careers in direct service delivery, the changes would likely be rather minor, with the biggest challenge being how to demarcate the two phases of training (i.e., the Foundational Knowledge and Competency Phase and the Focused Competency Phase). Fortunately, attempts to address this challenge can build on work already devoted to the subject of how to structure training for clinical psychologists (e.g., Hannay et al., 1998; Klepac et al., 2012). Likewise, it is expected that whatever changes are considered in doctoral programs and beyond will build on the competencies movement and literature (e.g., Kaslow et al., 2007; Rodolfa \& Schaffer, 2019). To the degree that doctoral programs wish to prepare students for career paths other than direct service delivery, the changes would be more extensive and challenging.

In theory, doctoral training programs can make whatever changes they wish. However, in practice, there are several potentially significant obstacles to change. First, we can envision remarkably few, if any, doctoral programs being willing to give up their accreditation, which would likely be the outcome of enacting the sorts of changes we are proposing (e.g., despite providing all students with foundational direct service competencies, not preparing all of them for doctoral level practice; granting the doctoral degree prior to completion of the internship). Therefore, for our proposal to be implemented, changes to accreditation criteria would be critical.

Those doctoral training programs that wish to continue preparing their graduates for doctoral level direct service delivery (which we would expect to be almost all programs, at least initially) would be extremely reluctant to make changes that would prevent their graduates from 
being well prepared to do so. They would therefore be extremely unlikely to implement our recommendation to make internship post-doctoral unless the internship programs themselves were willing to convert their pre-doctoral internships to post-doctoral internships. Although the only significant difference between the current predoctoral internship and the proposed postdoctoral internship is that in the latter the doctoral degree would be granted prior to beginning the internship (instead of it being granted at the conclusion of the internship), it would ultimately be up to the internships to decide if they were willing to do so.

Doctoral training programs would also be extremely unlikely to adopt our proposed changes if doing so were to adversely affect the ability of their graduates to obtain doctoral level licensure. Because the training of students pursuing careers delivering doctoral level direct service delivery in our proposed system would be almost identical to that obtained in the current system, the changes that would need to be made to the licensure system to accommodate the proposed changes would be negligible. The proposed model would continue to support the goal of state licensing bodies to protect the public regarding the direct provision of clinical services (i.e., assessment and therapy). Under the proposed model, eligibility for licensure at the doctoral level will require that students not only graduate with their doctoral degree, but also complete postdoctoral training in direct service delivery that satisfies a state's requirements for training beyond practica. We recommend that the year long full-time direct service delivery postdoctoral internship (that would replace the current predoctoral internship) fulfill such requirements. Essentially, whatever laws or rules guide licensure in any given state would need to be amended to state that a postdoctoral internship was necessary (as opposed to a predoctoral internship being necessary). But, it would ultimately be up to the state licensing boards to decide if they were willing to do so. That said, if the relevant accrediting agencies (specifically, the 
APA Commission on Accreditation (APA-CoA) and the Psychological Clinical Science Accreditation System (PCSAS)), the Association of Psychology Postdoctoral and Internship Centers (APPIC), the American Board of Professional Psychology (ABPP), and the Association of State and Provincial Psychology Boards (ASPPB) were to agree on changes and recommend model legislation/rules, licensing laws/rules across the country could be changed.

If our proposal were to be adopted, it may well have an impact on reimbursement for direct services delivered by: (a) graduate students after they obtain Master's level licensure; and (b) interns, since they will have their doctoral degree when they begin their internship. Changes in reimbursement have the potential to be beneficial or harmful depending on one's perspective. For example, sites at which advanced graduate students provide direct service delivery may be able to obtain higher levels of reimbursement when those graduate students have Masters level licensure. Likewise, internships may be able to obtain higher levels of reimbursement when their interns already have doctoral degrees. Interns may be in a position to expect higher salaries when they already possess a doctoral degree than when they do not. On the other hand, if interns' salaries increase, and the increased salaries are not matched by increased reimbursement, it could lead to a reduction in the number of internship positions available.

Although any change will bring with it a set of challenges (e.g., financial, political), we think the challenges should be thought of as hurdles to be overcome and not as obstacles to stand in the way. We are optimistic that an open process of discussion can lead to creative, successful solutions. We encourage all critical stakeholders - including (but not limited to) accrediting bodies, licensing boards, professional organizations, training coalitions, and organizations that represent graduate students, doctoral training programs, and internships - to sponsor activities evaluating the merits of our proposal, including, for example, conducting student surveys, 
commissioning a feasibility assessment and a white paper on change management, or sponsoring a series of small conferences dedicated to the ideas outlined here. We also think there is a critical role to be played by organizations that represent consumers (such as the Anxiety and Depression Association of America, Mental Health America, and the National Alliance on Mental Illness) as well as government agencies whose mission is to reduce mental health burdens (such as the National Institute of Mental Health and the Substance Abuse and Mental Health Services Administration) since ultimately it is consumers and society as a whole that have the most to gain or lose from changes (or the lack thereof).

For the kinds of changes to the training of clinical psychologists that we think are necessary, it will take a combination of top down and bottom up efforts. Top down changes (led by organizations such as those referred to earlier, as well as others, such as the Academy of Psychological Clinical Science (APCS), the Council of University Directors of Clinical Psychology (CUDCP), and the National Council of Schools and Programs of Professional Psychology (NCSPP)) will make it easier for programs to consider making the innovative bottom up changes that we think will ultimately be most important. The path forward will ultimately be driven from the bottom up as well, including by students as a central driving force of what they want their training to include. A useful historical example is the growth of the field of health psychology. Health psychology did not emerge as a vibrant subfield of clinical psychology because it was spawned by a national organization. Rather, individual psychologists saw opportunities and took advantage of them. These trailblazers created a path that others could follow (Wallston, 1997). As the numbers of clinical psychologists following this path grew, they formed interest groups and eventually independent divisions of larger national organizations (e.g., Section 2 of Division 18 of the American Psychological Association, succeeded by 
Division 38 [Health Psychology] of the American Psychological Association), independent national organizations (e.g., Society for Behavioral Medicine), and created doctoral and internship programs that focused primarily on the training of health psychologists.

New trailblazers will be needed to implement whatever changes the field chooses to pursue. Trailblazers are, by definition, exceptional. We do not expect many graduate students or early career clinical psychologists to explore relatively uncharted territory. Initially, not many individuals or training programs will take advantage of the increased opportunities that our proposal would enable. But, for example, just as some faculty had the vision and boldness to begin the field of health psychology, bringing venturesome students along with them, we expect a similarly new group of innovators and students to take the first risky steps to develop and expand new opportunities for clinical psychology to reduce mental health burdens. Given the public health significance, we expect that, with time, many graduate students and training programs will follow. To support innovation and to support individuals wishing to venture into relatively uncharted territory, we hope professional organizations will coordinate more mentorship and training opportunities with people who already use their degrees in nontraditional ways.

Because our proposed changes would lead to greater variation across doctoral programs (particularly during the second phase of training), prospective students would likely have greater difficulty deciding where to apply and matriculate. This will make it more important than ever for doctoral programs to communicate clearly to prospective students any program-specific goals, objectives, and competencies, including specific or unique education and training opportunities that are available (or not available) and preparation for licensure at the master's or doctoral level about what prospective students can expect. It will also be valuable for doctoral 
programs (or at least organizations that represent them) to communicate directly with undergraduate advisors about changes in the field and steps prospective students could take to learn about their graduate school options. We would also hope that institutions and training programs would allow more flexibility for students to receive training at across different programs (e.g., a program that specializes in dissemination and implementation could allow a student who desired more exposure to policy training to do an 'exchange' semester or practicum at a program with more of policy focus).

We have proposed momentous changes that will require a great deal of debate, refinement, and thoughtful reflection. Although this will take some time, we must keep in mind that the pursuit of perfection is the enemy of the good. Ultimately, we are optimistic that the field of clinical psychology will have the desire, courage, and wisdom to move on from the status quo and instead make changes that enable clinical psychology to contribute significantly to reducing mental health burdens. 
Training Clinical Psychologists

\section{References}

Albee, G. W. (1959). Joint Commission on Mental Illness and Health monograph series: Vol. 3. Mental health manpower trends: A report to the staff director, Jack R. Ewalt. New York, NY, US: Basic Books. http://dx.doi.org/10.1037/11514-000

Albee, G. W. (1990). The futility of psychotherapy. Journal of Mind and Behavior, 11(3-4), 369384. Retrieved from https://search-proquestcom.proxy2.library.illinois.edu/docview/617926404?accountid=14553

American Psychological Association (2019). Clinical Psychology. Retrieved from https://www.apa.org/ed/graduate/specialize/clinical

Andrilla, C.H.A., Patterson, D.G., Garberson, L.A., Coulthard, C., \& Larson, E.H. (2018).

Geographic variation in the supply of selected behavioral health providers. American Journal of Preventive Medicine, 54 (6: Supplement 3), S199-S207. Doi:

https://doi.org/10.1016/j.amepre.2018.01.004

Atkins, M. S., \& Frazier, S. L. (2011). Expanding the toolkit or changing the paradigm: Are we ready for a public health approach to mental health? Perspectives on Psychological Science, 6(5), 483-487. doi:http://dx.doi.org.proxy2.library.illinois.edu/10.1177/1745691611416996

Baer, D. M., Wolf, M. M., \& Risley, T. R. (1968). Some current dimensions of applied behavior analysis. Journal of Applied Behavior Analysis, 1, 91-97.

Baker, T. B., McFall, R. M., \& Shoham, V. (2008). Current status and future prospects of clinical psychology: Toward a scientifically principled approach to mental and behavioral health care. Psychological Science in the Public Interest, 9, 67-103. doi:http://dx.doi.org.proxy2.library.illinois.edu/10.1111/j.1539-6053.2009.01036.x 
Baxter, A. J., Scott, K. M., Ferrari, A. J., Norman, R. E., Vos, T., \& Whiteford, H. A. (2014). Challenging the myth of an "epidemic" of common mental disorders: Trends in the global prevalence of anxiety and depression between 1990 and 2010. Depression and Anxiety, 31, 506516.

Beck, J. G., \& Cody, M. W. (2016). Prevention of mental disorders. In J. Norcross, G. VandenBos, \& D. Freedheim (Editors-in-Chief), L. Campbell, M. Domenech Rodriguez, R. Krishnamurthy, B. Olatunji, \& N. Pole (Associate Editors), APA handbook of clinical psychology: Vol. 3. Applications and methods. Washington, DC: American Psychological Association.

Benjamin, L. T., Jr. (2005). A history of clinical psychology as a profession in America (and a glimpse at its future). Annual Review of Clinical Psychology, 1(1), 1-30. doi:http://dx.doi.org.proxy2.library.illinois.edu/10.1146/annurev.clinpsy.1.102803.143758

Berenbaum, H., \& Shoham, V. (2011). Broad and cutting-edge training in applied psychology: A clinical science perspective. Training and Education in Professional Psychology, 5(1), 22-29. doi:http://dx.doi.org.proxy2.library.illinois.edu/10.1037/a0022603

Boggs, K. R., \& Douce, L. A. (2000). Current status and anticipated changes in psychology internships: Effects on counseling psychology training. The Counseling Psychologist, 28(5), 672-686. doi:http://dx.doi.org.proxy2.library.illinois.edu/10.1177/0011000000285005

Bronfenbrenner, U. (1977). Toward an experimental ecology of human development. American Psychologist, 32(7), 513-531. doi:http://dx.doi.org.proxy2.library.illinois.edu/10.1037/0003066X.32.7.513

Bureau of Labor Statistics, U.S. Department of Labor (2018). Occupational Outlook Handbook, Retrieved from https://www.bls.gov/ooh/ 
Committee on training in clinical psychology. Recommended graduate training program in clinical psychology. (1947). American Psychologist, 2(12), 539-558.

doi:http://dx.doi.org/10.1037/h0058236

Cummings, N. A. (1995). Impact of managed care on employment and training: A primer for survival. Professional Psychology: Research and Practice, 26(1), 10-15. doi:http://dx.doi.org.proxy2.library.illinois.edu/10.1037/0735-7028.26.1.10

Cummings, J.R., Lindsay, A., Clennon, J., Xu, J., \& Druss, B.G. (2017). Geographic access to specialty mental health care across high- and low-income U.S. communities. JAMA Psychiatry, 74 (5), 476-484. Doi: 10.1001/jamapsychiatry.2017.0303

Davidson, C. N. (2017). The new education: How to revolutionize the university to prepare students for a world in flux. New York, NY: Basic Books

Fairburn, C. G., \& Patel, V. (2017). The impact of digital technology on psychological treatments and their dissemination. Behaviour Research and Therapy, 88, 19-25. doi:http://dx.doi.org.proxy2.library.illinois.edu/10.1016/j.brat.2016.08.012

Falender, C. A., Burnes, T. R., \& Ellis, M. V. (2013). Multicultural clinical supervision and benchmarks: Empirical support informing practice and supervisor training. The Counseling Psychologist, 41(1), 8-27.

doi:http://dx.doi.org.proxy2.library.illinois.edu/10.1177/0011000012438417

Fisher, P. A., Beauchamp, K. G., Roos, L. E., Noll, L. K., Flannery, J., \& Delker, B. C. (2016). The neurobiology of intervention and prevention in early adversity. Annual Review of Clinical Psychology, 12, 331-357. doi:http://dx.doi.org/10.1146/annurev-clinpsy-032814-112855

Gottesman, I. I., \& Shields, J. (1972). Schizophrenia and genetics: A twin study vantage point Academic Press, Oxford. 
Gruber, J., Prinstein, M. J., Clark, L. A., Rottenberg, J., Abramowitz, J. S., Albano, A. M., . . Weinstock, L. M. (2020). Mental health and clinical psychological science in the time of COVID-19: Challenges, opportunities, and a call to action. American Psychologist, doi:http://dx.doi.org.proxy2.library.illinois.edu/10.1037/amp0000707

Guidelines for prevention in psychology. (2014). American Psychologist, 69(3), 285-296. doi:http://dx.doi.org.proxy2.library.illinois.edu/10.1037/a0034569

Hamp, A., Stamm, K., Lin, L., \& Christidis, P. (2016). 2015 APA Survey of Psychology Health Service Providers. Retrieved from: https://www.apa.org/workforce/publications/15-healthservice-providers/index.aspx

Hannay, J.H., Bieliauskas, L.A., Crosson, B.A., Hammeke, T.A., Hammsher, K. deS., \& Koffler, S.P. (1998). Proceedings of the Houston Conference on Specialty Education and Training in Clinical Neuropsychology. Archives of Clinical Neuropsychology, 13, 157-250.

Hedegaard, H., Curtin, S.C., \& Warner, M. (2018). Suicide rates in the United States continue to increase. NCHS Data Brief, No. 309. Retrieved from: https://www.cdc.gov/nchs/data/databriefs/db309.pdf

Humphreys, K. (1996). Clinical psychologists as psychotherapists: History, future, and alternatives. American Psychologist, 51(3), 190-197. doi:http://dx.doi.org.proxy2.library.illinois.edu/10.1037/0003-066X.51.3.190

Kaslow, N. J., Rubin, N. J., Bebeau, M., Leigh, I. W., Lichtenberg, J., Nelson, P. D., . . Smith, I. L. (2007). Guiding principles and recommendations for the assessment of competence. Professional Psychology: Research and Practice, 38, 441-451. doi:10.1037/0735-7028.38.5.441

Kazdin, A. E. (2017). Addressing the treatment gap: A key challenge for extending evidence-based psychosocial interventions. Behaviour Research and Therapy, 88, 7-18. 
Kazdin, A. E. (2018). Innovations in psychosocial interventions and their delivery: Leveraging cutting-edge science to improve the world's mental health. New York: Oxford University Press.

Kazdin, A. E. (2019). Annual research review: Expanding mental health services through novel models of intervention delivery. Journal of Child Psychology and Psychiatry, 60(4), 455-472. doi:http://dx.doi.org.proxy2.library.illinois.edu/10.1111/jcpp.12937

Kazdin, A. E., \& Blase, S. L. (2011). Rebooting psychotherapy research and practice to reduce the burden of mental illness. Perspectives on Psychological Science, 6, 21-37.

Kazdin, A. E., \& Rabbitt, S. M. (2013). Novel models for delivering mental health services and reducing the burdens of mental illness. Clinical Psychological Science, 1(2), 170-191.

Kessler, R. C., Berglund, P. A., Bruce, M. L., Koch, J. R., Laska, E. M., Leaf, P. J., et al. (2001). The prevalence and correlates of untreated serious mental illness. Health Services Research, 36(6 Pt 1), 987-1007.

Kessler, R. C., Demler, O., Frank, R. G., Olfson, M., Pincus, H. A., Walters, E. E., . . Zaslavsky, A. M. (2005). Prevalence and treatment of mental disorders, 1990 to 2003. The New England Journal of Medicine, 352(24), 2515-2523. doi:http://dx.doi.org.proxy2.library.illinois.edu/10.1056/NEJMsa043266

Klepac, R. K., Ronan, G. F., Andrasik, F., Arnold, K. D., Belar, C. D., Berry, S. L., . . Strauman, T. J. (2012). Guidelines for cognitive behavioral training within doctoral psychology programs in the United States: Report of the inter-organizational task force on cognitive and behavioral psychology doctoral education. Behavior Therapy, 43(4), 687-697. doi:http://dx.doi.org.proxy2.library.illinois.edu/10.1016/j.beth.2012.05.002 
Knapp, B., Bardenet, R., Bernabeu, M.O., Bordas, R., Bruna, M., Calderhead, B., et al. (2015) Ten simple rules for a successful cross-disciplinary collaboration. PLoS Computational Biology 11(4): e1004214. https://doi.org/10.1371/journal.pcbi.1004214

Koss, K. J., \& Gunnar, M. R. (2018). Annual research review: Early adversity, the hypothalamicpituitary-adrenocortical axis, and child psychopathology. Journal of Child Psychology and Psychiatry, 59(4), 327-346. doi:http://dx.doi.org/10.1111/jcpp.12784

Lau, J. Y. F., \& Eley, T. C. (2010). The genetics of mood disorders. Annual Review of Clinical Psychology, 6, 313-337. doi:http://dx.doi.org/10.1146/annurev.clinpsy.121208.131308

Leong, F. T., \& Kalibatseva, Z. (2011). Cross-cultural barriers to mental health services in the United States. Cerebrum: the Dana forum on brain science, 2011, 5.

Levenson, R. W. (2017). Clinical psychology training: Accreditation and beyond. Annual Review of Clinical Psychology, 13, 1-22. doi:http://dx.doi.org.proxy2.library.illinois.edu/10.1146/annurevclinpsy-021815-093559

Lilienfeld, S. O., Lynn, S. J., O'Donohue, W. T., \& Latzman, R. D. (2017). Epistemic humility: An overarching educational philosophy for clinical psychology programs. Clinical Psychologist, 70, 6-14.

Lin, L., Christidis, P., \& Stamm, K. (2016). Datapoint: Where are the highest concentrations of licensed psychologists? Monitor on Psychology, 47(3), p. 13.

Marzano, L., Bardill, A., Fields, B., Herd, K., Veale, D., Grey, N., \& Moran, P. (2015). The application of mHealth to mental health: Opportunities and challenges. The Lancet Psychiatry, 2(10), 942-948. doi:http://dx.doi.org.proxy2.library.illinois.edu/10.1016/S2215-0366(15)00268-0 
Mohr, D.C., M. Zhang, \& S.M. Schueller. (2017). Personal sensing: Understanding mental health using ubiquitous sensors and machine learning. Annual Review of Clinical Psychology, 13, 2347. doi:http://dx.doi.org/10.1146/annurev-clinpsy-032816-044949

Morrison, F. G., Miller, M. W., Logue, M. W., Assef, M., \& Wolf, E. J. (2019). DNA methylation correlates of PTSD: Recent findings and technical challenges. Progress in NeuroPsychopharmacology \& Biological Psychiatry, 90, 223-234. doi:http://dx.doi.org/10.1016/j.pnpbp.2018.11.011

Muñoz, R. F., Beardslee, W. R., \& Leykin, Y. (2012). Major depression can be prevented. American Psychologist, 67, 285-295. http://dx.doi.org/10.1037/a0027666

National Prevention Council. (2011). National prevention strategy: America's plan for better health and wellness. Retrieved from http://www.surgeongeneral.gov/initiatives/prevention/strategy/report.pdf

National Academies of Sciences, Engineering, and Medicine (2017). Training the Future Child Health Care Workforce to Improve the Behavioral Health of Children, Youth, and Families: Proceedings of a Workshop. Washington, DC: The National Academies Press. https://doi.org/10.17226/24877.

Novak, N. L., \& Brownell, K. D. (2011). Obesity: A public health approach. Psychiatric Clinics of North America, 34(4), 895-909. doi:http://dx.doi.org.proxy2.library.illinois.edu/10.1016/j.psc.2011.08.001

Peterson, R. L., Peterson, D. R., Abrams, J. C., \& Stricker, G. (1997). The national council of schools and programs of professional psychology educational model. Professional Psychology: Research and Practice, 28(4), 373-386. doi:http://dx.doi.org.proxy2.library.illinois.edu/10.1037/0735-7028.28.4.373 
Rodolfa, E., \& Schaffer, J. (2019). Challenges to psychology education and training in the culture of competence. American Psychologist, 74(9), 1118-1128.

doi:http://dx.doi.org.proxy2.library.illinois.edu/10.1037/amp0000513

Sarason, S. B. (2003). American psychology and schools: A critique. American Journal of Community Psychology, 32(1/2), 99-106.

Satcher, D. (2001). Mental Health: Culture, Race, and Ethinicity-A Supplement to Mental Health: A Report of the Surgeon General. Rockville, MD: U.S. Department of Health and Human Services, Substance Abuse and Mental Health Services Administration, Center for Mental Health Services.

Singla, D. R., Kohrt, B. A., Murray, L. K., Anand, A., Chorpita, B. F., \& Patel, V. (2017). Psychological treatments for the world: Lessons from low- and middle-income countries. Annual Review of Clinical Psychology, 13, 149-181. doi:http://dx.doi.org.proxy2.library.illinois.edu/10.1146/annurev-clinpsy-032816-045217

Steel, Z., Marnane, C., Iranpour, C., Chey, T., Jackson, J. W., Patel, V., \& Silove, D. (2014). The global prevalence of common mental disorders: A systematic review and meta-analysis 19802013. International Journal of Epidemiology, 43, 476-493.

Strüber, N., Strüber, D., \& Roth, G. (2014). Impact of early adversity on glucocorticoid regulation and later mental disorders. Neuroscience and Biobehavioral Reviews, 38, 17-37. doi:http://dx.doi.org/10.1016/j.neubiorev.2013.10.015

Trautmann, S, Rehm, J. \& Wittchen, H. (2016). The economic costs of mental disorders: Do our societies react appropriately to the burden of mental disorders? EMBO Reports, 17, 1245-1249.

U.S. Department of Health and Human Services (2016). Health Resources and Services Administration/National Center for Health Workforce Analysis; Substance Abuse and Mental Health Services Administration/Office of Policy, Planning, and Innovation. 2015. National 
Projections of Supply and Demand for Behavioral Health Practitioners: 2013-2025. Rockville, Maryland. Retrieved from https://bhw.hrsa.gov/sites/default/files/bhw/health-workforceanalysis/research/projections/behavioral-health2013-2025.pdf

Victor, R.G., et al. (2018). A cluster-randomized trial of blood-pressure reduction in black barbershops. New England Journal of Medicine, 378, 1291-301. DOI:

\subsection{6/NEJMoa1717250}

Vigo, D., Thornicroft, G., \& Atun, R. (2016). Estimating the true global burden of mental illness. The Lancet, 3(2), 171-178. doi: 10.1016/S2215-0366(15)00505-2.

Wallston, K. A. (1997). A history of Division 38 (Health Psychology): Healthy, wealthy, and Weiss. In D. A. Dewsbury (Ed.), Unification through division: Histories of the divisions of the American Psychological Association, Vol. 2, pp. 239-267). Washington, DC, US: American Psychological Association. http://dx.doi.org/10.1037/10234-009

WHO World Mental Health Survey Consortium (2004). Prevalence, severity, and unmet need for treatment of mental disorders in the world health organization world mental health surveys. (2004). JAMA: Journal of the American Medical Association, 291(21), 2581-2590. doi:http://dx.doi.org.proxy2.library.illinois.edu/10.1001/jama.291.21.2581

World Health Organization (2011). mHealth: New horizons for health through mobile technologies. Geneva: World Health Organization. 
Table 1. Sample Careers/Positions and their Required Training and Credentials

\begin{tabular}{|c|c|c|c|c|}
\hline Professional Title: & $\begin{array}{c}\text { Medical Center } \\
\text { Psychologist }\end{array}$ & $\begin{array}{l}\text { VA Research } \\
\text { Psychologist }\end{array}$ & $\begin{array}{c}\text { Community Mental } \\
\text { Health Center } \\
\text { Program Manager }\end{array}$ & $\begin{array}{c}\text { University Professor of } \\
\text { Psychology }\end{array}$ \\
\hline Weekly Activities: & $\begin{array}{l}\text { Works primarily as a } \\
\text { neuropsychologist, } \\
\text { providing clinical } \\
\text { services, teaching and } \\
\text { supervision }\end{array}$ & $\begin{array}{l}\text { Engages in an } \\
80 / 20 \\
\text { (research/direct } \\
\text { client care) split }\end{array}$ & $\begin{array}{l}\text { Coordinates wellness } \\
\text { programs and } \\
\text { conducts occasional } \\
\text { intake interviews }\end{array}$ & $\begin{array}{l}\text { Involved in research, } \\
\text { teaching, and clinical } \\
\text { supervision of common } \\
\text { mental disorders within } \\
\text { the training clinic }\end{array}$ \\
\hline $\begin{array}{c}\text { Foundational Direct } \\
\text { Client Care } \\
\text { Competency } \\
\text { Required? }\end{array}$ & Yes & Yes & Yes \\
\hline $\begin{array}{c}\text { Master's Level Direct } \\
\text { Client Care Licensure } \\
\text { Required? }\end{array}$ & Optional & Optional & Yes & Yes \\
\hline $\begin{array}{c}\text { Postdoctoral Direct } \\
\text { Client Care Internship } \\
\text { Required? }\end{array}$ & Yes & Yes & No & No \\
\hline $\begin{array}{c}\text { Postdoctoral Direct } \\
\text { Client Care Licensure } \\
\text { Required? }\end{array}$ & Yes & Yes & No & No \\
\hline $\begin{array}{c}\text { Board Certification } \\
\text { for a Psychological } \\
\text { Intervention and } \\
\begin{array}{c}\text { Assessment Specialty } \\
\text { Required? }\end{array}\end{array}$ & Yes & No & No & No \\
\hline
\end{tabular}


Training Clinical Psychologists

\section{Appendix 1}

\section{Training Domains}

Domain 1: Research Methods and Scientific Epistemology

Research methods and scientific epistemology are fundamental activities of a clinical psychologist, regardless of their ultimate career choice. For instance, someone who trains or supervises emerging clinicians will need to digest and synthesize the research literature on treatment outcomes and mechanisms of change to provide training in evidence-based approaches. Analogously, someone who works on dissemination and implementation of evidence-based approaches will need a firm understanding of the scientific method to determine best practices and evaluate their efforts. Thus, regardless of specific career path, this training is essential.

Training in research methods should include a review of common research designs used in psychology. Because the specific designs used will evolve over time, and their relevance will vary across subfields of clinical psychology, we expect the specific designs to be covered will vary from program to program (and, ideally, from student to student). The topics that we expect to have the most lasting importance are: (a) discussion of scientific values and practices, with an emphasis on open science practices that can promote replicability, such as sharing data and preregistration (a focus not yet a part of most clinical psychology training programs); (b) hypothesis generation and testing, including causal inference; (c) differences between confirmatory versus exploratory approaches, and the value and fit of each; and (d) consideration of common biases that often interfere with optimal research practices, like confirmation biases, along with discussion of various forms of validity and reliability and ways they influence design decisions. An important framework underlying this domain would be an emphasis on "epistemic humility" (humility regarding one's knowledge) - a rubric premised on the notion that we are all susceptible to biases and that science is the best means of compensating for them (Lilienfeld et al., 2017).

\section{Domain 2: Data Science and Statistics}

Clinical psychologists, even those involved in direct client care, should be fluent in the process of data quality assurance, as well as how to manage and curate datasets for interpretation by others. As the nature of data changes over time, so will the specifics of these tasks, but the 
same principles (that data should be open and interpretable to as many people as possible) will apply. Similarly, all clinical psychologists should be well versed in the statistical assumptions that underlie common methodological designs. As these designs become more complex, this may necessitate specialized training and even more frequent collaborations with statisticians. It is critical, however, that clinical psychologists are able to evaluate the statistical strength of a set of results and how to interpret those results accordingly, to avoid problems that arise when scientific claims go beyond the data available. This is in service of being a critical consumer of science, both within the field of psychological science, and across the many allied fields in which clinical psychologists may wish to collaborate.

\section{Domain 3: Ethics}

Although ethics training is not new, what is likely to change is the nature of the ethical dilemmas faced by clinical psychologists. Also, although there will always be sets of written principles, rules, and guidelines that clinical psychologists will need to be familiar with, as the ethical dilemmas we face become more complex, it will become increasingly important for training in ethics to be focused on the application of those principles, rules, and guidelines. Research is increasingly collaborative, interdisciplinary, and geographically dispersed. Thus, whereas in the past, most ethical dilemmas in research concerned participants, looking forward, many ethical dilemmas will concern collaborators. In the past, most training in research ethics was very inward looking - what do I need to do to protect my own research team and the participants in my research. Increasingly, however, attention is being paid to one's obligations to the field (issues relevant to replicability and the sharing of data, for example). Given that we expect less and less of the applied work of clinical psychologists to be in the form of direct client care, and that clinical psychologists will increasingly play roles in supervision, administration, consultation, etc., we also anticipate changes in the ethical dilemmas to be faced in these areas. Analogously, ethical questions about when and how widely to disseminate new services are going to come into focus as technology enables wider dissemination more rapidly. More generally, new sets of ethical dilemmas will also arise as proportionally fewer and fewer services are delivered one-to-one and face-to-face. The current discussions about technology-based and non-specialist provider-based delivery models of care illustrate some of the many shifts in ethical challenges facing the discipline. 
Training Clinical Psychologists

\section{Domain 4: Diversity and Individual Differences}

The practice of clinical psychology requires an understanding of the many individual differences and demographic, cultural, and contextual factors that influence human behavior. Diversity is a multifaceted construct encompassing differences both within groups and between groups - it refers to individual and social group differences including, but not limited to, learning styles, life experiences, race, ethnicity, class, gender identity, sexual orientation, age, country of origin, ability and health, as well as cultural, religious, political and other affiliations. Much of the current practice of clinical psychology takes an idiographic approach in that the individual person or case is considered the unit of analysis; however, individuals can only be understood within the broader context of their lives and socio-ecological factors (e.g., Bronfenbrenner, 1977). In addition to its role in the direct provision of services, training in diversity and individual differences is critical for other core activities of clinical psychologists, such as research, advocacy, and implementation and dissemination of the science. Importantly, the burden of mental health conditions is much greater for some people, such as members of cultural or ethnic minority groups, due in part to disparities in health care. Mental health disparities result from factors such as differential access to mental health services (due to availability, stigma, poverty, stereotyping, etc.), systematic racism, and lack of services that are culturally appropriate for the population in need. Clinical psychologists will be needed to develop, test, and implement new, scalable models of prevention and treatment delivery that are capable of reaching groups not well-served by the current delivery model (Kazdin, 2018, 2019). Furthermore, psychologists will play an increasingly important role in shaping, advocating for, and evaluating mental health public policy that addresses the needs of our diverse population, all the while recognizing that science is not value free and that racial color blindness has played a critical role in limiting the advancement of anti-racist policies and interventions across psychological science. Regardless of the specific content covered in this domain, training approaches that consider intersectionality, community partnership, and strength-based (vs. deficit) models will be important.

Domain 5: Psychopathology

If clinical psychologists are to contribute to the reduction of mental health burdens, they must be knowledgeable regarding the phenomenology, classification, epidemiology, etiology, 
and developmental course of psychopathology across the lifespan, as well as the contributions of psychopathology to psychosocial and biological outcomes and impairment. Consistent with the training foci outlined in this paper, we contend that training in psychopathology should reflect foundational principles in psychological science, drawing heavily from theories and knowledge from typical development and allied psychological disciplines (e.g., cognitive, developmental). Thus, we do not prescribe a focus on any given specific content (e.g., Diagnostic and Statistical Manual of Mental Disorders vs. Research Domain Criteria classification systems). Rather, rigorous training in psychopathology would introduce relevant theories and the scientific evidence base, and the limits thereof. Ultimately, clinical psychologists must learn how to translate basic science examining psychopathology into innovations in classification, prevention, intervention, dissemination, and implementation.

Domain 6: Assessment

Psychological assessment is a defining skill within clinical psychology and meaningfully differentiates it from other mental health fields. Historically, relative to others interested in mental health, clinical psychologists have been particularly sensitive to issues such as instrumentation, psychometrics, idiographic and nomothetic considerations, as well as scalability. Training in assessment will need to keep pace with, and be influenced by, technological innovations and the exploding availability of data. For example, in the future, assessment of suicide risk may depend as much, or more, on examination of social media data as on clinical interviews. To successfully engage in public health promotion and the prevention of mental health conditions, clinical psychologists will need to be adept at conducting assessments at multiple levels, ranging from individuals to neighborhoods to macro, social systems.

\section{Domain 7: Intervention}

Intervention is a broad umbrella category that includes multiple topics tied to promoting evidence-based prevention and treatment approaches. We argue that it is important for all future clinical psychologists, even those who will never provide direct client care after obtaining their doctoral degree, to obtain first-hand exposure to people suffering the burdens of mental health conditions and to the care they are receiving. Also important is exposure to prevention and early intervention programs. Without experiencing the very real challenges that arise when working with complex human beings and applying knowledge in real-world settings, novel services are 
likely to fail when they are adopted outside the laboratory. Further, to improve a system, it is important to first understand the strengths and weaknesses of the existing system, or there is a serious risk of repeating past errors and hitting old barriers. A sophisticated understanding of the phenomena we study follows from and is enriched by listening, observing, engaging, and partnering with persons with the lived experience. Direct exposure to people suffering from mental health conditions and to the services they are receiving is an excellent way to develop empathy, understanding and insight, and as a result, an excellent way to develop new hypotheses.

One critical component is training in the theories explaining, empirical research supporting, and application of evidence-based principles of behavior change. This approach is aligned with the principles of assessment described above as well as with efforts to advance research and practice tied to transdiagnostic mechanisms of change. Also critical is training in the systematic collection, analysis, and application of data for the purpose of monitoring progress (or lack thereof) and intervention outcome. It would be important to ensure some exposure to research and applied approaches across the lifespan. As time goes on, it will be increasingly important to provide training in the use of digital/mobile technologies for the purpose of intervention. We do not want to dictate a one-size-fits-all model for the amount of practical training that should be required, but believe exposure to diverse populations and settings is important to gain some appreciation for the variability in problem areas, delivery models, and challenges that can arise.

\section{Domain 8: Teaching/Training/Supervising/Mentoring}

If clinical psychology is to significantly reduce mental health burdens, it will be achieved by having an impact beyond the modest number of clients to whom we can directly provide services. One way for clinical psychologists to increase their impact is to teach, train, supervise, and mentor others (including, but not limited to, other aspiring or current clinical psychologists). Across the larger mental health and public health landscape, one recent development that we anticipate will continue is the role of clinical psychologists in program leadership positions (Baker, McFall, \& Shoham, 2008). In this capacity, regardless of whether people work at Research-1 institutions as scientists or in community-based mental health as program directors, the mentoring, teaching, and supervising of others will remain key tasks of the future. Increasingly, each of these domains has a body of foundational knowledge and empirical 
evidence (e.g., Falender, Burnes, \& Ellis, 2013) that can, and we argue should, be taught to clinical psychologists in training.

Domain 9: Leadership, Collaboration, and Communication

Clinical psychologists will increasingly work with non-psychologists (e.g., paraprofessionals, social workers, physicians, engineers and computer scientists, public policy analysts, lawmakers). To increase their impact, clinical psychologists must learn to lead, to collaborate, and to communicate. To be effective leaders, clinical psychologists need skills in how to evolve their own leadership style, develop a vision, build trust and respect with others, and inspire and motivate others to take part in their vision in a unified manner. These skills are applicable to a myriad of leadership roles that trainees could encounter as professionals - such as director of a clinic or treatment facility, clinical supervisor, principal investigator of a research lab, or professional association board president. There is no reason to expect clinical psychologists to reduce mental health burdens on their own. Innovative, successful prevention and treatment programs are likely to be interdisciplinary. Mental health research itself is becoming increasingly collaborative and interdisciplinary. Cross-disciplinary collaborations are key to finding solutions to pressing, global-scale societal challenges (Knapp et al., 2015). Thus, it is critical to train clinical psychologists to be capable of successfully collaborating in whatever professional roles they will play. To be able to lead and collaborate, clinical psychologists need to be able to communicate effectively with other clinical psychologists, with other kinds of professionals, and with the general public. Although scholarly writing is likely to continue to be important for many clinical psychologists, other forms of communication (e.g., via blog, media, tweet) are likely to become increasingly important.

\section{Domain 10: Background in Psychological Science}

Clinical psychologists are, first and foremost, psychologists. What distinguishes clinical psychologists from professionals with overlapping interests but whose training and background differs (e.g., psychiatrists, geneticists interested in psychopathology) is that the work of clinical psychologists is rooted in basic psychological science. We echo the view expressed by Berenbaum and Shoham (2011) that "the application of cutting edge theories and methods from areas outside of traditional clinical psychology will ultimately enable psychologists to understand, validly assess, and successfully modify the phenomena that are the subject of clinical 
psychology" (p. 23). We therefore believe it is critical that clinical psychologists receive training in fields of psychology outside of the clinical domain (e.g., social and developmental psychology). However, we do not assume that exposure to the same areas of basic psychology research (or basic research in other disciplines) will be critical for everyone. Following Berenbaum and Shoham (2011), we argue that "individualizing graduate students' training experiences will be superior to a 'one size fits all' approach" (p. 28). To be more specific, we argue that not all students should be required to possess a common set of knowledge outside of clinical psychology. Clinical psychologists in training, and the programs training them, will need to determine which areas of basic psychological science each individual student will need to develop expertise in to understand their clinically-relevant phenomena of interest. Thus, what we are recommending is that each student considers basic research relevant to their area of discovery and career path, as opposed to all students receiving the same exposure to broad and general, non-clinical psychology areas. This approach assumes that learning does not end after receipt of the doctoral degree; clearly, if someone switches their primary research, teaching, or policy focus, different areas of basic research will become important to learn. A lifelong learning model assumes that people will acquire the most relevant up-to-date knowledge as they need it. 


\section{Appendix 2}

\section{Comparison of Proposed Model to Current European Models}

Other countries follow models that differ from those currently employed in North America and that also differ from the model we are proposing. In general, those in Western Europe tend to separate training in the sciences from preparation for clinical practice to a greater extent than is currently done in the United States. The United Kingdom differentiates between a pure research doctorate in philosophy (PhD DPhil), which is almost exclusively focused on preparing students for a career in scientific research (although topics researched may be directly relevant to psychopathology or treatment), versus a "Professional Doctorate" in clinical psychology (DClinPsy), which focuses more on preparing students for a career in clinical practice and research specifically in the clinical area. Typically, the DClinPsy requires a systematic literature review, a piece of research focused on the provision of services, and a piece of theoretically driven empirical research; these are presented in the form of a portfolio or dissertation. The UK PhD DPhil requires no specific clinical training whereas the DClinPsy involves placements in a specified variety of service delivery settings over the first two years (working age adults, children/adolescents, intellectual disability, and older adults) and a full year elective placement in its third and final year. In essence, the UK PhD DPhil is more akin to $\mathrm{PhD}$ training programs in the US (but without clinical training), whereas the DClinPsy is more similar to the PsyD training programs in the US (but with more training in the sciences and the required pieces of empirical research in the form of the dissertation).

The German model is currently undergoing change but will most likely involve foundational training such as we describe above at the Master's level (with a 6 month clinical internship) that qualifies the student to sit for examination as a licensed psychotherapist, with another 3-5 years of specialized psychotherapy training required to sit for examination as a licensed specialized psychotherapist (in CBT, psychodynamic therapy, or systemic therapy). Sweden requires five years of training in a university program to become a psychologist, culminating in a written master's thesis and followed by a one-year internship to be boardcertified and to qualify for independent practice status. This is wholly separate from the four years of scientific training culminating in a written thesis that is required for a doctorate in 
psychology. One must have a master's degree in psychology (but not necessarily clinical training) to apply for a $\mathrm{PhD}$ program.

To the extent that there is a "European model" (there are differences across countries) it tends to allow for greater separation between scientific training and preparation for clinical practice in a manner that facilitates greater flexibility, but more separation than we favor. What the European models share with the North American approach is that non-research training is focused almost entirely on direct client care. Currently, as far as we are aware, there are no training models for doctoral level clinical psychologists that are designed to train people to engage in the breadth of professional activities (such as mental health policy analysis, directing clinics, programs, and agencies, and implementing and disseminating programs/interventions) that will maximize the likelihood of clinical psychologists contributing to significant reductions in mental health burdens. 